\title{
O juiz e o compartilhamento do mundo da vida
}

\author{
The judge and the sharing of lifeworld
}

\author{
Marcelo Rubin de Lima*
}

\begin{abstract}
Resumo: Neste artigo, o conceito de compartilhamento do mundo da vida de Alfred Schütz é utilizado para analisar a ação do juiz frente às inovações e novidades que os atores sociais em conflito trazem aos tribunais. Este é um problema que se apresenta para os juízes que se dedicam às causas ambientais, visto que as tradições do passado não podem ser reproduzidas por serem nocivas ao meio ambiente. $\mathrm{O}$ magistrado dirige suas palavras na sentença em direção aos nossos sucessores, às gerações futuras anônimas e indeterminadas. Estes aspectos foram trabalhados com apoio de entrevistas em profundidade e análises de textos jurídicos para estudar o caso do Quilombo da Família Silva, o primeiro quilombo urbano do Brasil. Constatamos que entre as capacidades de um juiz ambiental está a faculdade de autorizar o surgimento da inovação de que as novas gerações são portadoras. Desta forma ele consegue interromper uma tradição e iniciar uma nova cadeia de causa e efeito na sociedade.
\end{abstract}

Palavras-chave: Fenomenologia. Juiz. Quilombo. Inovação.

\begin{abstract}
In this article, Alfred Schütz's concept of sharing the lifeworld is used to analyze the judge's action facing innovations and novelties that conflicting social actors bring to the courts. This is a problem that is presented to judges who are dedicated to environmental causes, since the past traditions can not be reproduced because they are harmful to the environment. The magistrate directs his words in the sentence towards our successors, the anonymous and indeterminate future generations. These aspects were addressed with the support of in-depth interviews and the analysis of legal texts to investigate the case of the Quilombo da Familia Silva, the first urban reservoir of traditional land in Brazil. We find that among the capabilities of an environmental judge is the power to authorize the emergence of innovation whos carriers are the new generations. In this way he can break a tradition and start a new chain of cause and effect in society.
\end{abstract}

Keywords: Phenomenology. Judge. Quilombo. Innovation.

\footnotetext{
* Doutor em Sociologia pela Universidade Federal do Rio Grande do Sul (Ufrgs, Porto Alegre, RS, Brasil). Membro do grupo de pesquisa Magistratura, Sociedade e Política na mesma universidade<rubin.lima@ufrgs.br>.
}

Civitas, Porto Alegre, v. 17, n. 3, p. 504-522, set.-dez. 2017 


\section{Introdução}

Uma das grandes contribuições da sociologia fenomenológica de Alfred Schütz para o pensamento social é o conceito de compartilhamento do mundo da vida, a noção de que na sociedade compartilhamos nosso cotidiano com os que estão em nosso raio de ação, os nossos consócios e também com nossos contemporâneos, predecessores e sucessores. Schütz assinala que uma das características do mundo dos nossos sucessores é que ele é completamente indeterminável, não temos como prever suas identidades nem o conteúdo e sentido de suas ações. Esta perspectiva abre espaço para percebermos que a novidade e a inovação é uma característica de todos os nossos sucessores. Além disso, mesmo indeterminadas, em nosso cotidiano sempre encontramos quem oriente suas ações em direção às gerações futuras. Este é o caso dos juízes que se dedicam às causas ambientais. Este artigo trabalha com estes conceitos de Schütz para analisar a ação dos magistrados frente à novidade e inovação no tribunal.

Nosso recorte empírico é a $9^{\mathrm{a}}$ Vara Federal de Porto Alegre, vara especializada em conflitos ambientais que em sua criação herdou as causas ligadas à questão quilombola. O conflito que determinou a criação do primeiro quilombo urbano do Brasil é o caso que iremos tratar. Esta pesquisa é resultado de um estudo de caso sobre a vara ambiental de Porto Alegre e seu papel na criação do quilombo urbano dos Silva. Na parte empírica do trabalho nos valemos de entrevistas em profundidade e análise de documentos jurídicos. As entrevistas foram realizadas com ativistas do Movimento Negro Unificado e advogados ligados às causas ambientalistas e étnicas. Partimos da noção de que o crescimento da autoridade do juiz no cenário sociopolítico nacional é taken for grandet e que isso se relaciona com o abandono das características tradicionais deste ator social de primeiro plano.

Os conceitos de Schütz foram usados para interpretar os dados tanto das entrevistas quanto da pesquisa documental. Para isso orientamos a interpretação das falas e dos textos para distinguirmos quando o agente orienta sua ação para as gerações passadas ou futuras. Usamos a tipologia de Schütz de "antepassados" e "gerações futuras" como conceitos heurísticos na interpretação dos dados produzidos. Buscamos destacar os gestos, falas e palavras que denotam aspectos temporais da ação e expressões que revelam a surpresa dos agentes diante das construções sociojurídicas que surgiram do cruzamento entre a vara ambiental e as reivindicações quilombolas.

A seguir apresentaremos os conceitos de compartilhamento do mundo da vida de Schütz para em seguida apresentarmos os dados empíricos. Como 
conclusão destacamos que, ao contrário do que o senso comum possa indicar, o conceito de quilombo não se relaciona apenas com tradição, mas também com as exigências da reordenação de nossas práticas futuras. Esta é uma das características que guiou os juízes que atuam na criação da vara ambiental de Porto Alegre. Reside nesta característica uma das fontes de autoridade do juiz. Fato que é notado por diversos atores socais que percebem nos tribunais o melhor espaço para tratar das inovações que nos causam espanto e surpresa.

\section{Aspectos da sociologia de Schütz}

Alfred Schütz desenvolve sua sociologia fenomenológica a partir de dois grandes pilares (H. Santos, 2012): o primeiro, a filosofia de Edmund Husserl, o segundo, a sociologia compreensiva de Max Weber. Desta forma, Schütz realiza o movimento de aproximação da filosofia com a sociologia a partir de uma análise crítica da filosofia de Husserl para avançar seu próprio projeto de desenvolver uma fenomenologia do social. Para isso, ele busca superar alguns aspectos do pensamento de Husserl que lhe parecem problemáticos (Tellier, 2003), este é o caso da descrição da sociedade vista como um acordo entre todas as subjetividades individuais, como uma orquestração entre mônadas.

Para Schütz, isso indica que as relações sociais não podem ultrapassar os limites das relações intersubjetivas vivenciadas diretamente entre os atores sociais. Ao contrário desta posição, ele considera que o mundo social possui diferentes zonas espaciais e temporais, zonas que são mais próximas ou mais distantes de nossa experiência sensorial imediata. O sociólogo vienense nota que: "o mundo circundante (este termo sendo entendido aqui em um sentido sociológico) no qual você e eu nos sentimos um ao outro em imediatismo espacial e temporal" (Umwelt) é compartilhado também com nossos contemporâneos distantes (Mitwelt), nossos predecessores (Vorwelt) e sucessores (Folgewelt) (Schütz, 1975, p. 81).

Em seu artigo The problem of transendental intersubjectivity in Husserl (1975) Schütz observa que Husserl toma como modelo para o desenvolvimento de seu trabalho situações em que há a presença corporal dos participantes de uma comunidade, ou seja, quando um está no campo perceptivo do outro, em relações que podemos ver os gestos e ouvir as palavras de nossos interlocutores. Este é o cotidiano que compartilhamos com nossos próximos (Umwelt) que Schütz denomina de nossos consócios.

Contudo, Schütz questiona a valorização das relações presenciais, o face-a-face no aqui e agora, que coloca ênfase em alguns sentidos humanos 
em detrimento de outros, como é o caso do destaque dado para o olhar e a fala. Além disso, Schütz nota que "deve-se também perguntar se, de fato, a aparência corporal do 'Outro' em minha esfera primordial tem o significado decisivo que Husserl atribui a ele" (Schütz, 1975, p. 81). Neste sentido, o sociólogo argumenta que podemos ter mais afinidades com uma pessoa do passado, que portanto não nos é acessível diretamente, por exemplo, com Marx, do que com nosso vizinho de porta (leibhaftig), que nos é acessível de forma direta nos encontros casuais da vida cotidiana, mas que nos é estranho (Fremder).

Assim, Schütz percebeu que alguns dos problemas filosóficos enfrentados por seu mestre poderiam ser resolvidos com uma abordagem sociológica do ser social. Neste esforço para aproximar a fenomenologia filosófica da sociologia, Schütz construiu uma de suas maiores contribuições para o pensamento sociológico, a noção de que compartilhamos o mundo da vida com nossos próximos, os consócios, e também com nossos contemporâneos distantes (Mitwelt) que estão espacialmente ausentes e as outras gerações que se encontram temporalmente distantes.

Segundo Schütz, em primeiro lugar, convivemos com os que estão em nossa área de atuação, em seguida com nossos contemporâneos distantes, aqueles que estão no mundo no mesmo tempo que nós, porém estão não estão próximos. Em terceiro, também compartilhamos o nosso cotidiano com os nossos predecessores (Vorwelt), estes são aqueles que não estão mais aqui; por fim, compartilhamos este mundo com os nossos sucessores (Folgewelt), aqueles que ainda não nasceram e nem podemos supor quem serão.

\section{A realidade no mundo da vida e seu compartilhamento espacial}

Em sua obra Schütz propõe que a fenomenologia do social deve se preocupar com o cotidiano, nas situações em que os sujeitos mantêm uma atitude natural com relação a todos os objetos e demais participantes do mundo da vida. Ou seja, nos casos em que não se coloca em questionamento as manifestações e as coisas que compõem o nosso cotidiano. Tellier (2003, p. 58) comenta que "a intersubjetividade não é, aos olhos do sociólogo, um problema a ser resolvido no âmbito transcendental, mas como um fato (gegebenheit), como um dado do mundo da vida". Schütz (1993, p. 137) considera que "o homem em atitude natural compreende o mundo interpretando suas próprias vivências do Eu, são vivências de coisas inanimadas, de animais e de seus congêneres humanos". Hermílio Santos (2012) descreve estas relações no mundo da vida da seguinte forma: 
O mundo da vida (Lebenswelt) é o mundo intersubjetivo préexistente, assumido como dado pelo indivíduo a partir de uma "atitude natural", em que o indivíduo reconhece as coisas objetivas da vida, assim como as condições para a ação (por exemplo, as intenções dos outros e as suas próprias). Na atitude natural da vida cotidiana suspende-se a dúvida em relação à existência dessas próprias coisas, já que todas as experiências passadas estão presentes como que ordenadas, como conhecimento ou como consciência daquilo que se pode esperar que ocorra, pois "se assim foi, assim poderá ser". Entretanto, tudo aquilo que é considerado como dado (taken for granted) nas situações do mundo da vida é cercado de incertezas. Dessa maneira, a atitude natural se dá simultaneamente à interpretação por parte dos indivíduos, baseada, sobretudo, no estoque de conhecimento disponível ao indivíduo, ou seja, apoiada no "conhecimento à mão", que funciona como um "código de referência” para o indivíduo. Esse sistema de conhecimento - que é resultante da sedimentação de experiências subjetivas no mundo da vida - assume, para aqueles indivíduos que se reconhecem membros internos de um grupo ou comunidade, um aspecto de coerência necessário que permite que todos tenham uma chance razoável de compreenderem e serem compreendidos.

Nesta descrição, a noção de sedimentação de conhecimento possui centralidade, ela se refere a todo o conjunto de saberes que a sociedade dispõe para superar os problemas do cotidiano. Este conhecimento é como os sedimentos de um coral marinho, que podemos remover as camadas superficiais para nas camadas mais antigas tentarmos descobrir soluções para os problemas do cotidiano. Neste sentido, tudo o que é rotineiro na vida cotidiana não oferece problemas, sabemos como utilizar todas as ferramentas que nos cercam e nos orientamos nas ruas da cidade por roteiros preestabelecidos. Quando um problema ultrapassa a rotina de nosso cotidiano, devemos revirar nosso estoque de conhecimento para encontrarmos uma saída. Por exemplo, quando saio da minha casa em direção ao trabalho, e o caminho que costumo fazer encontra-se bloqueado, imediatamente tenho que utilizar alguma ferramenta, um GPS, ou experiências passadas para determinar um novo roteiro que me leve ao meu objetivo. Desta forma, a própria atividade rotineira "abre o primeiro plano para a deliberação e a inovação" (Berger e Luckmann, 2011, p. 76).

Em sua sociologia fenomenológica, Schütz constrói a noção de que compartilhamos o mundo da vida no sentido de que, em nosso presente, vivemos em um "aqui e agora" geograficamente determinado, que podemos acessar diretamente e que compartilhamos intersubjetivamente com os demais 
membros da sociedade com quem nos relacionamos em nossa área de atuação (cf. Berger e Luckmann, 2011). Isso garante que nossos órgãos dos sentidos, nosso olhar, nosso tato, nossos ouvidos captem e interpretem as mesmas sensações dos outros que compartilham o mesmo "aqui e agora".

Desta forma, os que compartilham o mesmo cotidiano percebem a mesma temperatura ambiente, utilizam as mesmas ferramentas e sentem as mesmas alegrias e tristezas que envolvem eventos sociais, como uma partida de futebol. Tudo isso é possível com a simples presença do outro, esta é a nossa realidade imediata. Para Berger e Luckmann (2011, p. 40), isso ocorre porque "o mundo da vida cotidiana proclama-se a si mesmo" e sua contestação ou superação teórica requer consideráveis esforços.

Entretanto, também podemos acessar em nosso cotidiano outras realidades que estão na nossa área de atuação e interferem nos nossos sentidos. Berger e Luckmann (2011, p.43) comentam que a realidade da vida cotidiana nos é apresentada de diversas formas, todo o mundo da vida é estruturado no espaço e no tempo, e isso indica que existem zonas que são acessíveis diretamente pela nossa experiência imediata e zonas que não são acessíveis diretamente. Além disso, podemos compartilhar e viver diversas realidades que se sobrepõem à realidade cotidiana.

Estas realidades que se sobrepõem ao nosso cotidiano, mas que podemos acessar, são como pequenas saídas do nosso horizonte de entendimento. A saída da realidade cotidiana pode ser vivida em conjunto com os nosso consócios. Para demostrar estas situações, Berger e Luckmann (2011) usam o exemplo das experiências estéticas ou religiosas: quando estamos em sessão de umbanda ou de cinema, somos transportados para mundos longínquos e imaginários que possuem significados próprios e que vivenciamos com intensidade ao lado de indivíduos que passam pelas mesmas sensações.

Porém, imediatamente após a experiência estética ou religiosa ter tomado conta de nossos sentidos, no final do culto ou da sessão de cinema, somos conduzidos imediatamente de volta à realidade do cotidiano que compartilhamos com nossos próximos, e assim, percebemos que nossas experiências cotidianas compartilhadas são plenamente reais, o trajeto que faremos para chegar em casa e a qualidade do transporte são aspectos que se impõem sobre a realidade que vivenciamos nas experiências religiosas e estética que acabamos de presenciar na igreja ou no teatro. Estes são aspectos da realidade espacial do cotidiano que compartilhamos com nossos próximos. A seguir, iremos apresentar alguns aspectos do compartilhamento temporal do mundo da vida que se referem aos nossos contemporâneos, predecessores e sucessores. 


\section{O compartilhamento temporal do mundo da vida}

No aspecto temporal de nossa experiência cotidiana também percebemos os que estão no mundo da vida no mesmo tempo que nós, porém não estão próximos de nossa área de atuação. Esses são os nossos contemporâneos, aqueles que não temos contato face-a-face no aqui e agora. Estes podem ser antigos amigos de infância que estão distantes, mas que estão em nossa memória ou são os indivíduos que se encontram em outro país assistindo a um jogo de futebol. Os contemporâneos são os que vivem em outro lugar e nunca tivemos contato direto, mas sabemos de sua existência. Todos eles, embora distantes espacialmente de nossa posição aqui agora, são pessoas que compartilham com nós a mesma época, o mesmo tempo.

Desta forma, mesmo que as experiências intersubjetivas não sejam vivenciadas diretamente, compartilhamos com os nossos contemporâneos diversas experiências e preocupações, como são as alterações no clima, a busca por uma alimentação mais saudável ou o gosto pelo esporte, todas questões que compartilhamos de maneira mais ou menos direta. Assim, Schütz (1979, p.217) esclarece que nosso contemporâneo "é alguém que sei que coexiste comigo no tempo, mas que não vivencio imediatamente" e desta forma, sempre conhecemos nossos contemporâneos de forma "indireta e impessoal".

Outro aspecto do compartilhamento temporal do mundo a vida é que vivemos em um mundo já povoado de objetos com significados socialmente compartilhados (Berger e Luckmann, 2011). Esta é a base da noção de que vivemos em uma teia de relações que nos é apresentada como sendo a realidade cotidiana, isto é, aquilo que parece e aparece para mim e para todos que compartilham o mundo conosco. Isso indica que o nosso cotidiano já está completamente dotado de significação. Todas as ferramentas que utilizamos e todas as instituições que nos cercam são dotadas de sentidos e significados que já estão dados e não participamos de sua construção. Estes objetos do mundo da vida e seus significados já estavam estabelecidos antes de nosso surgimento na terra. Assim, podemos constatar que os automóveis esportivos, os clubes de futebol e as relações étnicas são objetivadas e dotadas de sentido social que não foi estabelecido por nós.

O compartilhamento temporal do munda da vida é notado de várias formas, por exemplo, mantemos um diálogo com os nossos predecessores nos livros e nas histórias que foram contadas. Isso indica que, embora somos fadados a desaparecer do mundo, sempre deixamos nossa autoria em obras como os poemas e as leis. Desta forma, segundo Schütz (1979, p. 228), “quando leio um documento histórico, posso me imaginar face a face com o seu autor e saber 
dele através de seus contemporâneos; um por um, seus contemporâneos tomam seus lugares dentro do meu mundo dos predecessores". Schütz comenta que o mundo dos nossos predecessores é acessado por nós de maneira semelhante com a que apreendemos o mundo de nossos contemporâneos, aqueles que estão distantes de nossa área de atuação, fazemos isso, embora não com a mesma precisão, com a utilização de tipos ideais segundo os conceitos da sociologia de Weber, estes tipos ideais servem de guia para interpretarmos as situações em que se encontravam os nossos predecessores.

Schütz (1993, p. 163) comenta que quando lemos um livro ocorre uma interpretação quase simultânea na qual o leitor do presente revive a escolha de palavras do autor do passado como se isso ocorresse diante de seus próprios olhos. Para Schütz (1993, p. 134), decorre disso a constatação de que a nossa coexistência corporal não é essencial para compreensão dos outros, afinal, podemos ligar as mentes e intensões de pessoas de épocas diferentes em uma quase simultaneidade com a nossa mente, fazemos isso observando os escritos, a música, arte e lendas das gerações passadas.

Berger e Luckmann (2011) lembram que a linguagem é o sistema de sinais mais importante da sociedade. E tudo o que conhecemos e objetivamos na vida cotidiana é mantido pelas gerações que se sucedem principalmente pela linguagem que usamos. Para os autores, a linguagem sempre exerce efeitos coercitivos sobre quem a manipula, somos desde sempre forçados a entrar em seus padrões para podermos ser compreendidos pelos demais agentes do mundo da vida. E assim, temos a linguagem como uma instituição, Berger e Luckmann consideram que as instituições são produtos de uma história, de um contínuo de tipificações recíprocas e habituais, desta forma a linguagem une diferentes gerações e:

Devido a esta capacidade de transcender o "aqui e agora", a linguagem estabelece pontes entre diferentes zonas dentro da realidade da vida cotidiana e as integra em uma totalidade dotada de sentido. As transcendências têm dimensões espaciais, temporais e sociais. Por meio da linguagem posso transcender o hiato entre minha área de atuação e a do outro, posso sincronizar minha sequência biográfica temporal com a dele, e posso conversar com ele a respeito de indivíduos e coletividades com os quais não estamos agora em interação face a face. Como resultado dessas transcendências, a linguagem é capaz de "tornar presente" uma grande variedade de objetos que estão espacial, temporal e socialmente ausentes do "aqui e agora". [...] No que diz respeito às relações sociais, a linguagem "torna presente" a mim não somente os semelhantes que estão fisicamente ausentes no momento, mas indivíduos no passado relembrado ou reconstruído, assim como outros projetados como 
figuras do imaginário futuro. Todas estas "presenças" podem ser altamente dotadas de sentido, evidentemente, na contínua realidade da vida cotidiana (Berger e Luckmann, 2011, p. 58).

E assim, a linguagem cotidiana organiza campos semânticos que se formam com as experiências biográficas e históricas que são guardadas e acumuladas. É desta forma que determinamos o que será lembrado e o que será esquecido em nossas experiências cotidianas. Contudo, este modelo só é verdadeiro com nossos contemporâneos, consócios e predecessores. Isso ocorre porque o mundo dos predecessores já aconteceu, e nada mais poderá ser mudado, este é um mundo completamente acabado.

Por sua vez, o mundo de nossos sucessores é livre por excelência, completamente livre e não-histórico, afinal, ele ainda não aconteceu, não temos nenhum relato nem mesmo as palavras necessárias para descrever o mundo de nossos sucessores que ainda não existem. $\mathrm{O}$ mundo dos sucessores não pode ser projetado nem planejado porque não sabemos e nem mesmo podemos imaginar o que irá intervir neste mundo que está em um futuro distante. Schütz apresenta o mundo dos nossos sucessores da seguinte forma:

Para fechar o círculo da nossa visão do mundo social, tratemos brevemente do mundo dos sucessores. Se o mundo dos predecessores é completamente fixo e determinado, o mundo dos consócios livre e o mundo dos contemporâneos provável, o mundo dos nossos sucessores é completamente indeterminável. Nossa orientação com relação a nossos sucessores não pode ir além disso: que vamos ter alguns deles. Nenhuma chave abrirá a porta desse domínio, nem mesmo a dos tipos ideais. Pois este último método baseia-se em nossa experiência de predecessores, consócios e contemporâneos, e não há nenhum princípio que nos permita estendê-lo ao mundo de nossos sucessores. É claro, alguns de nossos consócios e contemporâneos vão viver mais do que nós e podemos supor que vão continuar a agir então como sabemos que agem agora. Desse modo, uma espécie de zona de transição pode ser estabelecida entre os dois mundos. Mas quanto mais distanciado é o mundo dos predecessores do Aqui e Agora, menos se pode confiar em tais interpretações (Schütz, 1979, p. 229).

Desta forma, Schütz enfatiza que nossas relações com os predecessores e sucessores são anônimas. Berger e Luckmann (2011) esclarecem que o anonimato dos predecessores é representado com designações imprecisas, nos referimos a eles como os pais fundadores, os imigrantes ou os heróis da pátria. Já os sucessores são comumente referidos como nossos netos ou 
simplesmente as gerações futuras. Todas estas tipificações (2011, p. 52) são projeções substancialmente vazias, pois são quase completamente destituídas de conteúdo individualizado. Contudo, mesmo anônimas, estas tipificações são realidades na vida cotidiana e se manifestam de forma muito decisiva visto que sempre há quem está disposto a se sacrificar pelos heróis da pátria ou pelas gerações futuras. No quadro abaixo apresentamos as diferentes esferas do mundo social e seu compartilhamento.

Quadro 1. O compartilhamento do mundo social de Schütz

\begin{tabular}{|l|l|}
\hline Mundo social & Compartilhamento \\
\hline Consócios & O mesmo tempo e espaço (o aqui e agora). \\
\hline Contemporâneos & O anônimo, mesmo tempo em espaço diferente. \\
\hline Predecessores & O passado anônimo já realizado e determinado. \\
\hline Sucessores & O futuro anônimo e impredizível. \\
\hline
\end{tabular}

Assim, parafraseando Schütz (1975, p. 81), deve-se também perguntar se, de fato, as características impredizíveis do compartilhamento do mundo da vida com os nossos sucessores têm o significado decisivo que Schütz atribui a ele. Acreditamos que esta questão não tenha recebido a devida atenção com relação a suas consequências. Todos os nossos sucessores, próximos ou distantes, tem a capacidade de introduzir no mundo da vida algo inteiramente novo que não foi sequer pensado ou imaginado pelas gerações do passado distante ou próximo. Os que nascem, além de receberem as tradições do passado, também trazem consigo o dom de introduzir a novidade no mundo da vida. Neste sentido, a atuação de nossos sucessores não se limita a soma das circunstâncias do presente, eles são mais que isso, porque eles têm a capacidade de produzir a inovação radical no cotidiano.

Como nós, os nossos sucessores no mundo não serão apenas imitadores das ações do passado; ao contrário, eles buscarão sua própria inspiração e assim produzirão uma abordagem própria do mundo que herdarão. Isso indica que, além de removermos o estoque de conhecimentos do passado, produzimos novos conhecimentos e soluções para os problemas inéditos do cotidiano. Se voltarmos ao exemplo da linguagem, devemos pensar que, sempre que falamos, modificamos a língua que herdamos, e nesse processo de mudança da língua acrescentamos ou suprimimos algumas expressões e criamos ou esquecemos de outras. Afinal, se não acrescentarmos novos vocábulos e estilos linguísticos a linguagem cotidiana se petrifica e perde a sua capacidade de composição 
poética e retórica, ela se converte em uma linguagem sem evolução, incapaz de dar conta da complexidade semântica do mundo da vida.

\section{O juiz e o compartilhamento do mundo da vida}

Os conceitos de compartilhamento do mundo da vida de Schütz são tratados por Myriam Revault d'Allonnes em sua obra Le pouvoir des commencements: essai sur l'autorité, que trabalha com a relação entre a autoridade e os novos começos, ou seja, a novidade. Para a autora, se o espaço é a matriz do poder, o tempo é a matriz da autoridade. Isso ocorre porque as manifestações da autoridade se dão em um mundo do qual a estrutura sempre é temporal, pois todas as sociedades são distribuídas no espaço e no tempo. Etimologicamente as palavras autoridade e autor têm origem comum, a raiz da palavra autor se refere ao indivíduo que age e toma uma iniciativa no sentido de promover, criar e garantir alguma coisa no tempo. Por sua vez, a autoridade é o que autoriza o novo começo, no sentido de que toda palavra pronunciada com autoridade determina uma mudança e cria qualquer coisa que é a "qualidade misteriosa de produzir a existência" (D'Allonnes, 2006, p. 72).

A relação com o tempo faz com que a autoridade tenha uma característica geracional que é a possibilidade de estabelecer a ligação entre as diferentes gerações que compartilham o mundo da vida. Isso permite estabilizar a ação humana no tempo. Quem age com autoridade garante a perenidade a partir da transmissão das experiências dos que já foram para os que ainda estão por vir. E assim, quem age com autoridade também é responsável por autorizar às novas gerações a faculdade de iniciar uma nova série de eventos que não foi sequer pensada pelas gerações passadas.

A relação da autoridade com o tempo é um problema que se coloca para todo o juiz que irá julgar um caso ambiental, visto que as práticas produtivas herdadas do passado não protegem o meio ambiente, e assim, o magistrado deve identificar e indicar novas práticas sociais e econômicas para os litigantes. A atuação jurisdicional de uma vara ambiental trabalha com a perspectiva de que ela deve interromper uma tradição e lançar uma nova perspectiva para a sociedade e seu entorno. Isso indica que a ação de um juiz ambiental está ligada diretamente à questão do compartilhamento do mundo da vida.

Em nossa pesquisa, encontramos um bom exemplo de orientação temporal para o futuro nos artigos do desembargador Cândido Leal Jr., que foi o primeiro juiz titular da $9^{\text {a }}$ Vara Federal de Porto Alegre. Nestes textos percebemos que a preocupação com os aspectos compartilhados do mundo 
da vida estavam delineados desde a fundação da vara em 2005. Naquele momento, Leal Jr. comentou suas expectativas com relação à especialização da justiça da seguinte forma:

Se a Justiça Federal obtiver êxito na especialização, a vara ambiental será um instrumento da cidadania e da proteção da vida na busca do indispensável equilíbrio das forças econômico-sociais com o que ainda resta da natureza, com condições de preservar a memória das gerações passadas (meio ambiente cultural) e assegurar qualidade de vida às gerações presentes e futuras (meio ambiente natural e urbano) (Leal Jr., 2006, p. 24).

A preocupação geracional é um componente da atuação dos magistrados que se dedicam às causas ambientais (Tessler, 2008, 2003). O primeiro aspecto desta preocupação geracional é verificado nas sentenças que são como um marco deixado para as gerações futuras, para que elas possam compreender os fatores que levaram o juiz a tomar a sua decisão. Sete anos após a fundação da vara ambiental, Leal Jr. comenta este aspecto da seguinte forma:

Outra peculiaridade das ações ambientais é que deixam marcas na história da comunidade. Embora muitas vezes a memória social seja fraca e os responsáveis sejam muitas vezes esquecidos, o que é decidido nos processos ambientais repercute no tempo e no espaço de determinada comunidade. Por isso, é essencial que esse juiz demonstre os motivos de seu convencimento, exibindo às partes, à sociedade e ao futuro as razões que o levaram a decidir (Leal Jr., 2012, p.9).

Esta orientação geracional, com ações que ligam as diferentes gerações foi decisiva para o movimento quilombola. Em 2005, no início de suas atividades, a vara ambiental herdou seis processos ligados à causa quilombola, entre estes dois são relacionados com a comunidade quilombola da família Silva: os processos 2005.71.00.019117-8 e 2005.71.00.020104-4 que resultaram na criação do primeiro quilombo urbano do Brasil.

Neste processo, os juízes da vara ambiental fizeram visitas ao quilombo e foram apoiados por laudos técnicos do Incra e do Ministério Público. Na ação civil pública no 5043925-95.2013.4.04.7100/RS o Ministério Público Federal argumentou que, segundo os conceitos de minoria étnica "pode-se inserir a comunidade quilombola família Silva, uma vez que esta comunidade se constitui em grupo organizado em torno do histórico e cultura quilombolas, 
autodeterminando-se conforme sua origem e ascendência que remetem aos quilombos e à resistência à escravidão".

A base jurídica do reconhecimento da identidade quilombola está a constituição de 1988, no artigo 68, que concede: "aos remanescentes das comunidades dos quilombos que estejam ocupando as suas terras é reconhecida a propriedade definitiva, devendo o estado emitir-lhes os respectivos títulos". Contudo, a regulamentação deste artigo só ocorreu em 2003 com o decreto $\mathrm{n}$ - 4.887, quando a categoria jurídica remanescentes das comunidades dos quilombos foi determinada como:

Art. $2^{\mathrm{O}}$ Consideram-se remanescentes das comunidades dos quilombos, para fins deste Decreto, os grupos étnico-raciais, segundo critérios de autoatribuição, com trajetória histórica própria, dotados de relações territoriais específicas, com presunção de ancestralidade negra relacionada com a resistência à opressão histórica sofrida.

$\S 1$ 을 Para fins desse Decreto, a caracterização dos remanescentes das comunidades dos quilombos será atestada mediante autodefinição da própria comunidade (Decreto n. 4.887).

Não deixa de causar espanto como que, com pouca representação política, os quilombolas conseguiram garantir seus direitos na constituição de 1988. O interessante notar aqui é que, tanto quilombolas, quanto ambientalistas possuem uma mesma narrativa dos fatos, ambos consideram que a garantia desses direitos foi influenciada pelo descaso das forças políticas conservadoras em relação à real situação quilombola e ambiental. Nas entrevistas colhemos os seguintes relatos que se cruzam:

Então esta discussão veio com força e de certa forma com o racismo em 88 contraditoriamente, porque os caras tinham esta visão de quilombo, que eram poucos e bem longe, e aí os caras pensaram: "Vamos deixar esta porra passar e tal porque aí deixa pra lá e não nos incomodamos". Aqui também, são 13 quilombos e isso não é nada. Na época eu me lembro teve um Fórum Social Mundial de 2001, e pelo livro do mapeamento dos quilombos no Brasil, do Rafael Santos de Araújo, ele apontava que aqui havia 8 comunidades quilombolas no estado, e a urbana que tinha era os Silva né. Aí tu vê, hoje são 69 comunidades quilombolas com processo aberto no Incra (entrevista adv 1).

$\mathrm{Na}$ área ambiental houve a mesma percepção, de que muitos direitos ambientais foram aceitos porque não se levava a sério estas questões e por isso foram integradas ao texto constitucional: 
É por isso que te digo, o direito ambiental ele foi todo construído numa questão que teve uma evolução, ele passou porque ele não era exercido, o código florestal existe desde 65 e não era exercido, então deixa ele lá porque nunca cumpriam nada. Aí começa a ter exigência do cumprimento das regras e isso gera oposição. Ninguém exigia, ninguém cumpria, não se fazia valer aquele direito. Aí no momento que tu começa a ter o Ministério Público atuante, que os órgãos ambientais começam a fiscalizar e a sociedade se interessa, a partir deste momento vem todo um movimento de oposição tentando reverter as regras ambientais (entrevista adv 2).

A sentença que criou o quilombo da família Silva foi escrita pelo juiz Cândido Leal Jr. quando ele apontou os limites jurídicos da posse da terra. Este foi um marco para a resistência quilombola no Brasil. No terceiro ponto de sua argumentação, o magistrado demostra sua autoridade quando utiliza a faculdade de produzir a existência. Neste item de sua sentença ele apresenta a seguinte argumentação que relaciona a propriedade da terra e o tempo em nosso código legal:

Terceiro, porque posse e propriedade não são relações estáticas no tempo, que se consumam num único momento, que sejam exauridas ou cristalizadas no exato instante em que reconhecidas. São relações continuativas, que dependem do tempo, que produzem efeitos no tempo, dia após dia, instante após instante. São influenciadas pela passagem do tempo e pelo que acontece no mundo fático e no mundo jurídico, tanto que o Código Civil prevê situações em que a propriedade e a posse são adquiridas (arts. 1204-1209 e 1238-1274 do CC) ou perdidas (arts. 1223-1224 e 1275-1276 do $\mathrm{CC}$ ), evidenciando que são relações dinâmicas, que se sucedem e produzem efeitos no tempo (Juiz Leal JR., sentença quilombo família Silva 11 jul. 2005).

A seguir apresentaremos o Quilombo da Família Silva e alguns aspectos da resistência quilombola na cidade de Porto Alegre.

\section{O quilombo da família Silva}

A etimologia da palavra quilombo está ligada a diversas línguas africanas. No idioma Bantu (Lopes, 1988; Leite, 2008), quilombo significa acampamento guerreiro na mata. A palavra quilombo também possui um significado histórico que está ligado ao Quilombo de Palmares. Freitas (1973) comenta que em 1597 o Brasil já possuía uma expressiva população de negros fugidos das lavouras de cana-de-açúcar. Simone R. dos Santos (2012) identifica a origem jurídica do conceito de quilombo em 1741, quando o Conselho Ultramarino de Portugal 
determinou como quilombo todas as terras de negros que fugiam dos trabalhos forçados na lavoura.

Foi a partir da abolição da escravatura que o termo quilombo ganhou um significado sociocultural que designa uma forma de organização própria dos libertos que se coloca como uma alternativa à sociedade branca. Leite (2008) identifica um processo de dessemantização histórica do termo quilombo, que em alguns momentos representa uma aproximação com a sociedade branca e em outros momentos um distanciamento. Já para os ativistas do movimento negro, o conceito de quilombo significa a reunião das diversas práticas e experiências de resistência dos afrodescendentes contra a opressão.

A construção social do conceito de quilombo urbano foi fruto de uma antiga luta que envolve memórias de tempos passados e práticas do presente. Nas entrevistas colhemos depoimentos que descrevem a luta contra a opressão na cidade de Porto Alegre:

Aqui em Porto Alegre e na cidade de Guaíba tem duas localidades que têm tudo a ver com isso. Vocês conhecem o Bairro Tristeza não é? Ali onde era o fórum, era a sede de uma fazenda e do outro lado da Tristeza, em Guaíba tem a praia que é a Alegria. Então esta era a rota de fuga. Tinha todo um esquema, porque boa parte do transporte era feito por negros, quem trabalhava no remo, então tinha acordos pra dar guarida, e esta era a rota econômica do estado, através do mar interior até as charqueadas, até aquela região. E o Uruguai já tinha abolido a escravidão (entrevista $\mathrm{adv} 1$ ).

O quilombo dos Silva foi formado por uma família que tem suas origens geográficas ligadas aos campos da região central do estado do Rio Grande do Sul, que se territorializou no bairro Três Figueiras na cidade de Porto Alegre. Estes são os avós e os pais dos atuais moradores do quilombo. Sua cultura, no entanto, tem ligação com a ocupação por escravos de região que liga o litoral norte ao planalto norte do estado, segundo os relatos de campo: "então, ali se tu pegar os mais velhos ali, eles têm memória ainda de congada, entendeu, porque a origem do tronco é da região dos Campos de Cima da Serra, São Francisco de Paula, que tem toda aquela ligação com o litoral (fazendo um $\mathrm{S}$ com a mão) (entrevista adv. 1).

Sob o ponto de vista urbano, este caso tem início no processo de expansão centrífuga da cidade de Porto Alegre. Processo que se iniciou com a construção do Cais Mauá e o projeto de urbanização e branqueamento das regiões centrais da cidade, na primeira metade do século vinte. Neste momento, as áreas tradicionais ocupadas por descendentes de escravos foram paulatinamente se deslocando para regiões mais distantes do centro da cidade. 
Sempre pressionadas pela expansão imobiliária, as comunidades quilombolas que se encontravam nas proximidades das novas áreas urbanizadas buscavam dissimular a sua presença para não serem perseguidas pelos novos moradores. Ficar desapercebido e se misturar aos demais trabalhadores era uma das táticas de resistência:

Se tu pegar boa parte dos quilombos urbanos, eles estão não direto nas grandes vias, eles estão nas rebarbas, e são áreas que são assim, quando vai abrindo as vias elas vão aparecendo porque vai se valorizando o entorno e que aí vem... (fazendo sinal com os dedos que significa pauladas), porque durante muito tempo a tática foi se fingir de morto pra ver se não me pega (entrevista adv 1).

Foi desta forma que o conceito de quilombola se afasta da tradição e passa a ser percebido como um conjunto de práticas cotidianas de resistência cultural à dominação. Este é um conceito do passado com uma nova interpretação que aponta para ações do presente e do futuro. Foi esta a novidade que deixou muita gente estupefata. No trabalho de campo, colhemos comentários que se referiam com espanto à noção de quilombos urbanos. Percebemos isso em expressões como: "Tinha escravos na cidade é? Pensei que era só na lavoura". Até mesmo os ativistas ligados à cultura afro e aos movimentos negros ficaram surpresos, nas entrevistas colhemos o seguinte comentário que expõem o impacto desta nova construção sociojurídica:

E o quilombo dos Silva foi o primeiro quilombo urbano do Brasil! Eu me lembro disso, a gente não sabia que existia quilombo no Rio Grande do Sul né, quilombo era coisa de Alagoas e Pernambuco né... Eu, por exemplo, a gente já militava na capoeira e já falávamos de quilombo. Aí quando saiu isso, aí eu pensei, mas um quilombo ali no foco, do lado do Iguatemi (shopping center) mas da onde os caras conseguiram isso? Sabe de uma coisa, assim... impensada né! Impensável assim! Como é que os caras conseguiram isso? Aí que deu aquele bah! Pô (gesticulando com as mãos para o alto), aí eu me lembro, primeiro reconhecido e bá! (entrevista ativista 1).

A família Silva desde meados do século 20 ocupa uma das áreas mais valorizadas da cidade de Porto Alegre. Inicialmente, segundo relatos, sua terra correspondia a aproximadamente três campos de futebol. A primeira ação da família Silva para garantir a posse da sua terra foi de usucapião em 1972. Nesta ação os membros da família ainda são tratados como posseiros e invasores. Após sucessivas derrotas na justiça, sua área foi reduzida a um campo de futebol. Mas a partir da criação da 9a Vara Federal a família viu sua sorte 
mudar quando seu caso passou a ser tratado como o de um quilombo urbano. $\mathrm{Na}$ entrevista este momento foi narrado da seguinte forma pelos ativistas que participaram do processo de titulação do quilombo:

Estava lá na Constituição Federal, e nós trouxemos isso pro urbano, existia uma visão pictórica folclórica da questão da resistência territorial negra desvinculada da questão pertencimento e da cidade, a maior parte da população negra vivia na cidade. E eles tentaram esgrimir a disputa do território pelo direito digamos comum, o direito civil do usucapião, aí na verdade não deu certo. E nós, o MNU (Movimento Negro Unificado) tínhamos toda uma tradição da questão da própria discussão da questão quilombola, foi toda uma mobilização para gravar na Constituição federal de 88 , nós tivemos dois ou três encontros anteriores à questão do reconhecimento dos territórios, então nós pensamos, por que não no urbano? Afinal de contas a maior parte da população mora na cidade, e aí nós fizemos esta abordagem, fizemos a interlocução com o Ministério Público Federal (MPF) que ajudou bastante, na época era o Dr. Marcelo Beckhausen é tudo muito novo pra todo mundo (entrevista $\operatorname{adv} 1)$.

Neste momento foram decisivas duas liminares, a primeira que trancou a ordem de despejo, a segunda que confirmou a posse da terra para os Silva. $\mathrm{Na}$ linguagem dos militantes do Movimento Negro Unificado, MNU, a expressão "dar uma trancada" se refere a ação jurídica que visa interromper o processo de esbulho que a especulação imobiliária faz contra as comunidades quilombolas. A primeira "trancada" foi inédita e foi descrita da seguinte forma nas entrevistas pelos advogados do MNU:

Na prática era uma novidade no espaço urbano. Aí nós sugerimos que, dentro do trâmite que tinha, que se fizesse um termo de reconhecimento de posse pelo Incra que já estava com o processo aberto e nós utilizamos este termo de reconhecimento de posse, neste agravo que é... e aí saiu aquela famosa decisão do juiz, muito boa, do juiz plantonista, dando uma primeira trancada de que juiz não é Deus e tal e que tinha que reconhecer a posse... Depois que a gente deu essa primeira trancada teve um prazo de quatro, cinco dias aí entrou Ministério Público Federal, Ministério Público Estadual, Fundação Cultural Palmares e o Incra com uma ação de manutenção de posse, se conseguiu também reforçar essa liminar na Justiça Federal aí teve o deslocamento da competência para a justiça federal, aí deu uma trancada razoável, forte no processo e aí foi aquele imbróglio, os próprios racistas do setor imobiliário não tinham muita propriedade do que estava acontecendo (entrevista adv 1). 
Após estas ações, a luta pela retomada dos territórios quilombolas em Porto Alegre tomou um novo rumo, a perspectiva de derrotas nas esferas administrativas e judiciais se inverteu. $\mathrm{Na}$ esteira da vitória dos Silvas outras áreas quilombolas urbanas foram reconhecidas como são os casos do quilombo dos Alpes, quilombo da família Fidélix e quilombo do Areal da Baronesa. Além disso, o Movimento Negro Unificado intensificou sua luta pelo reconhecimento das terras quilombolas em outras áreas da cidade.

\section{Considerações finais}

Nesta pesquisa utilizamos as ferramentas teóricas da fenomenologia de Schütz para constatar que devemos incluir na ação dos magistrados a faculdade de autorizar um novo começo para os atores que são vítimas de longas cadeias de causa e efeito, como é o caso da luta quilombola pela retomada de suas terras. Sob ponto de vista jurídico, a interrupção de uma tradição que agride a natureza ou os grupos humanos só ocorre quando a novidade que se manifesta como o inesperado aparece nas palavras de uma sentença, este é o direito realizado, que transforma em ação as construções jurídicas dos códigos legais. Assim, no caso estudado percebemos que a ação do magistrado é capaz de iniciar um novo começo que aponta para um futuro que, embora impredizível, comporta a inovação dos nossos contemporâneos e sucessores no sentido de Schütz.

Identificamos que a grande conquista da 9a - Vara Federal de Porto Alegre, e das varas especializadas em geral, é que elas facilitam o encontro entre magistrados especializados e a queixa social que as novas gerações trazem consigo. Neste sentido, a ação do juiz é como um medium que liga as diferentes gerações que compartilham o mundo da vida. As palavras na sentença do magistrado proporcionam a ligação entre a novidade e inovação que é proposta pelos nossos contemporâneos e sucessores com a obra já acabada e realizada dos nossos predecessores. Esta ligação entre a tradição e a inovação se manifesta na cena social ao nos causar surpresa e espanto. $\mathrm{O}$ reconhecimento pelos atores sociais da autoridade do juiz ambiental está também apoiado nestes fatores.

\section{Referências}

BERGER, Peter; LUCKMANN, Thomas. A construção social da realidade. Petrópolis: Vozes, 2011.

D'ALLONNES, Myrian. Le pouvoir des commencements: essai sur l'autorité. Paris: Seuil, 2006.

FREITAS, Décio. Palmares, a guerra dos escravos. Porto Alegre: Movimento, 1973. 
LEAL JÚNIOR, Cândido. Inventário da jurisdição ambiental em Porto Alegre: primeiros dias da vara federal ambiental, agrária e residual. Revista CEJ, v. 10, n. 33, p. 22-29, 2006.

LEAL JÚNIOR, Cândido. O projeto socioambiental da Justiça Federal da 4⿳ạ região. Revista CEJ, v. 16, n. 58, p. 88-99, 2012.

LEITE, Ilka Boaventura. O projeto político quilombola: desafios, conquistas e impasses atuais. Estudos Feministas, v. 16, n. 3, p.965-997, $2008<10.1590 /$ S0104026X2008000300015>.

LIMA, Marcelo. A justiça e a cidade: o juiz nas lutas pela ocupação do espaço urbano de Porto Alegre. 2017. Porto Alegre, 2017. Tese de doutorado, Programa de PósGraduação em Sociologia, Universidade Federal do Rio Grande do Sul.

LOPES, Nei. Bantos, malês e identidade negra. Rio de Janeiro: Forense Universitária, 1988.

SANTOS, Hermílio. Ação, relevância e interpretação subjetiva. Estudos de Sociologia, v. 1, n. $18,2012$.

SANTOS, Simone Ritta dos. Comunidades quilombolas: as lutas por reconhecimento de direitos na esfera pública brasileira. Porto Alegre, 2012. Tese de doutorado, Programa de Pós-Graduação em Serviço Social, Pontifícia Universidade Católica do Rio Grande do Sul.

SCHÜTZ, Alfred. La construcción significativa del mundo social: introducción a la sociología comprensiva. Barcelona: Paidós, 1993.

SCHÜTZ, Alfred; WAGNER, Helmut (orgs.). Fenomenologia e relações sociais. Rio de Janeiro: Zahar Editores, 1979.

SCHÜTZ, Alfred. The problem of transcendental intersubjectivity in Husserl. In: Collected papers III: Studies in phenomenological philosophy. The Hague: Martinus Nijhoff, 1975. p. 51-91.

TELLIER, Frédéric. Alfred Schutz et le projet d'une sociologie phénoménologique. Paris: PUF, 2003.

TESSLER, Marga Inge Barth. O juiz e a tutela ambiental: a fundamentação das sentenças. Revista CEJ, v. 12, n. 41, p. 4-10, 2008.

TESSLER, Marga Inge Barth. O juiz e a tutela jurisdicional do meio ambiente. Novos Estudos Jurídicos, v. 8, n. 2, p. 355-369, $2003<10.14210 /$ nej.v8n2.p355-370>. 